\title{
The Influence of Family Dynamic, Attachment to Fathers, Attachment to Friends, Self-esteem, and Stress on School Adaptation: A Comparative Study of Adolescents from Non-military Families and Military Families
}

This study examined the factors that influenced school adaptation by adolescents from non-military families and military families; subsequently, our research targeted 387 middle school children located in Chungnam province. Questionnaires were used and data analysis was conducted by $t$-tests and multiple regression analysis. The results were as follows: First, adolescents from non-military families perceived higher levels of attachment to fathers and selfesteem than adolescents from military families. However, the stress level for adolescents from military families was higher than adolescents from non-military families and adolescents from non-military families adapted better to school than adolescents from military families. Secondly, family dynamic, attachment to fathers, and stress influenced school adaptation by adolescents of non-military families and family dynamic and the attachment to friends influenced the adaptation to school by adolescents from military families.

School is a place of learning where students develop values and attitudes. It is also a place of socialization

Doctoral Student, Department of Child \& Family Studies, The Catholic University of Korea, Seoul, Korea (ysk7744@hanmail.net)

Corresponding Author: Professor, Department of Child \& Family Studies, The Catholic University of Korea, Seoul, Korea (mhyukj@catholic.ac.kr)

Key Words: Adolescents, Family dynamic, Attachment to fathers, Attachment to friends, Self-esteem, Stress, School adaptation where adolescents prepare their future lives in society as well as a place to gain knowledge. How students adapt themselves to school is an important issue because they can establish a sense of identity and learn about interpersonal skills that can influence their lifestyle. School is the extended social ground from home and is a place that can influence the socialization of adolescents directly or indirectly; however, many adolescents complain about difficulties and dissatisfaction with school.

Adolescents experience physical, cognitive, emotional development through the transitional period from the childhood to adulthood. Adaptability is highlighted during this period while these various changes are happening (Lee, 2005).

School adaptation is defined as an active and creative process to balance school environments and individuals by changing the school to satisfy personal needs as well as internally changing to meet the requirements of the school (Danielsen, 2009). School adaptation by adolescents requires a positive attitude towards school and the display of socially and emotionally desirable behaviors (Min \& Kawn, 2004) and it also defined as active participation in educational process to develop intelligence and moral character (Kim, 2009). Scholars have differed on the exact definitions of school adaptation; however, school adaptation is a vital element for the social and 
emotional development of adolescents (Burchinal, Roberts, Zeisel, \& Rowley, 2009). It is perceived as an important element because it can significantly influence adaptability to society.

School adaptation is the ability to cope with internal situations and adapt to a school environment where adolescents spend the majority of their time. Active participation in school can influence personal growth and developments (Lim \& Lee, 2007). This serves an initiation into a society that they will experience as adults; however, a failure to adapt can cause stress, bullying, school violence and problematic behavior such as drug abuse, depression, and suicide (Lee, 2001).

Korea remains the only divided country in the world and has the highest proportion of soldiers per capita (including professional soldiers) in Asia. Military power is significant in terms of both expenditures and population. Korea maintains both a professional and a conscript soldier system. The professional soldier system allows individuals to serve and build a financially stable long-term career in the military (Choi, 2009). However, the children of soldiers are raised in unique circumstances; and face frequent migration due to station transfers. School age children of military families are known to experience psychological conflicts due to the absence of fathers in unstable household environments and unique educational environments (Choi, 2005). The occupational characteristics of soldiers influence household environments and rearing attitudes towards children (Lee, 1983). It is reported that adolescents from military families have more difficulty to adapt to school than adolescents from non-military families due to frequent changes in schools (Kang, 2000). Conversely, adolescents from military families and adolescents from non-military families perceived the same level of quality of life and the characteristics of military families did not influence the quality of life for school age children or their behavioral patterns in the study of Choi (2005). Marchant and Medway (1987) claimed that frequent migration and frequent changes in schools themselves did not negatively influence children. Moon (2009) stated that the cultural experiences that adolescents from military families have through frequent school changes widened their understanding of new worlds and improved adaptability; however, there were some problems and the ability to utilize interpersonal skills to deal with emotions. Korea remains the only divided country in the world with a significant soldier population; therefore, it is necessary to look at inconsistent previous research results and understand if the frequent environmental changes experienced by adolescents from military families negatively influence their adaptability versus the experiences of adolescents from non-military families.

Related school adaptation variables can be classified into family related variables, friend related variables and individual related variables. Family relationship has recently been emphasized in research that emphasizes family benefits from a family relationship point of view (Bascoe, Davies, SturgeApple, \& Cummins, 2009; Nam \& Park, 2009). Shek (2002) said that a smoothly function family has a positive impact on psychological status and mental health. Research results into family and school adaptation indicate a correlation between of these two (Choi, 2010; Lee, 2005; Lim \& Lee, 2006). Caldwell, Wieve, \& Cleveland (2006) claim that family dynamic (such as intimacy and kindness) and family structural factors influence school adaptation.

Parental attachment influences the mental stability of adolescents that helps facilitate school adaptation (Jee, 2001) and it is reported that the positive impact of parent-child relationships increases at the beginning of middle school (Bascoe, Davies, SturgeApple, \& Cummins, 2009). Attachment is a continuous interpersonal emotional bond (Ainsworth \& Bell, 1970) and the attachment function in life development theory is to conquer environments and continuously develop self-esteem and social ability throughout life (Kalish \& Knudston, 1976). Attachments formed as a teenager are important for development and adaptation during adolescence. Fostering was considered the role of the mother in the past and fathers were emotionally distant and authoritarian; however attitudes have changed as fathers increasingly help raise children (Morman \& Floyd, 2002). More emphasis is placed on the roles of fathers as disparities in the two parental roles for each parent disappear (Yoon, 1998). However, existing research on 
attachment is mainly on infants and mother and child attachment rather than research about attachment between fathers and adolescents.

Research by Lim (2006) on middle school students showed that the functional communication manners of fathers were related to relationships with teachers, friends, study participation and compliance with rules. Lee (2005) said that there were more difficulties to adapt to school when students enter into problem orientated communications with fathers. Research results also indicated that the adaptability of children to society increased if a father acted responsibly towards his role (Park, 2003). Flouri and Buchanan (2004) discovered that the participation of the father in fostering is related to the competence in studying of the children. Research results suggest that fathers influence the adaptation to school by children. The research by Moon (2009) on adolescents from military families examined the level of school adaption and the frequency of conversation with fathers. Children who conversed with fathers were more likely to adapt successfully to schools and this suggests an intimate relationship with the father; consequently, smooth communication is important for school adaptation.

Different types of parental attachments are established during adolescence (Lee, 2005); consequently, friends are also considered suitable subjects for attachment and relationships (Freeman \& Brown, 2001). Friendship during adolescence provides emotional support to adolescents (Youniss \& Smollar, 1985) as well friends play an influential and large role on individual development and social adaptation (Suh \& Yoo, 2001). Friendship during adolescence is extremely important because adolescents obtain self-control and independence as well as identities outside the control of parents as the importance of friendship increases (Shim, 2003). The relationship with parents or adults have hierarchy feature; however, the relationship with friends is equal. A relationship with friends is significant to learn socialization (Kim, 2002). Other studies indicated the importance of friendship during adolescence. Laird, Petti, Dodge, and Bates (1999) showed that adolescents felt that they were supported, secure and had less conflict when a mutual relationship with friends was established; consequently, they were able to play protective roles towards antisocial behavior. Barnnow, Lucht, Freyberger (2005) and Chapple (2005) showed that adolescents misbehave more often when rejected by friends. The research of Lim and Lee (2007) indicated that the group with a better relationship with friends adapted better to school and that friendship is the most influential variable to predict school adaptation. The research of Ahn (1983) on high school students showed that students from military families have more difficulties in the establishment of good relationship with others.

Self-esteem also exists as an individual related variable. Self-esteem is defined as a positive selfevaluation and the overall evaluation of values that includes personal expectations to his ability (Baumeister, Dori, \& Hastings, 1998; Brown \& Mankowski, 1993) or self-value or self-importance compared to others (Long, Henderson, \& Ziller, 1968). Adolescence is an important time that depends on positive and high self-esteem in regards to personal pride, creativity and productivity; however, low self-esteem lowers a sense of pride and instigates a sense of incompetence (Lim \& Lee, 2007). Positive or negative self-perceptions influence personal behavior related to school adaptation and misbehavior (Jung, 2002). Important role models such as parents, teachers and friends influence the self-respect of adolescents and the satisfactory experiences with these individuals help increase the sense of self-respect (Lim \& Lee, 2007). A high sense of self-respect during growth and development provides a sense of ownership and the ability to perceive themselves as a valuable human being. Adolescents receive a sense of pride in whatever they do and are able to cope with unexpected changes (Yang, 2002).

Adolescents with high self-respect actively cope with stress (Yoon, 2004) and experience less loneliness (Lim \& Rah, 2003); however, adolescents with low self-respect tend to have episodes of depression, mental health problems (D'Zurilla \& Nezu, 2007) and behavior problems (Daane, 2003; McGee \& Williams, 2000). The relation between a sense of self- 
respect and school adaptation is important. The research by Yang and Yoo (2003) as well as Lee (2009) showed that a sense of self-respect is the single most influential factor that influences school adaptation. Kim (2003) and Lim and Lee (2007) argue that the group with a higher sense of selfrespect had a higher level of school adaptation. Researchers have also stated there was a significant correlation between self-respect and school adaptation (Gweon \& Yang, 2007; Shim, 2003) that is related to school adaptation as well as school performance (Jung, 2005).

Adolescence is a period of physical and emotional instability when adolescents worry about interpersonal relationships. Families, studies, grades, friends, and appearance worry many adolescents; consequently, stress occurs with excessive requirements to adapt (Kim, 2001). Stress during adolescence is a developmental risk factor rather than a positive force that significantly influences adaptability and emotional adjustment (Agnew, Brezina, Wright, \& Cullen, 2002). Significant areas of stress for teenagers are school, friend and family that can have a negative impact on daily lives; consequently, there is an increased rate of suicide and suicidal thoughts (Lee, 2004). Mental health problems (such as anxiety or depression) in adolescents hinder the wholesome development of themselves as well as the family and society (Moon, 2008). Research on the relation of the daily stress and school adaptation discovered that the students who had more daily life stress experienced difficulties to adapt to school (Kim, 2004; Kim, 2008). Research by Kim (2001) on soldiers and their children showed that adolescents who stayed less than 1 year at one school perceived more stress in regards to friendship than those who stayed longer than 3 years. It is possible to assume that the adolescents of soldiers who had frequent school transfers will have higher levels of stress than non-military adolescents.

These various reports indicate that school adaptation by adolescence cannot be explained by a single variable such as family, friends and each individual's characteristics; school adaptation has multi-dimensional systems and relations. Consequently, all factors are classified into family-related factors, friend-related factors and person-related factors for an investigation of how they relate to school adaptation. Family-related factors included family dynamic, the attachment to fathers, friend-related factors included attachment to friends and personrelated factors included self-esteem and stress factors. This study also searched for programs that improve school adaptation as related to the unique characteristics and individualities of non-military adolescents and the adolescents from military families to provide a foundation for educational programs. This study provides basic information to adolescents so that they can successfully adapt to society as independent adults.

The following questions are posed according to research goals.

<Question 1> Are there differences in family dynamic, attachment to the father and friends, selfesteem, stress and school adaptation between adolescents from non-military families and adolescents from military families?

$<$ Question 2> What are the variables that affect school adaptation by adolescents from non-military families and adolescents from military families?

\section{METHODS}

\section{Subject}

With a purposive sampling method, a total of 470 questionnaires were distributed to middle school students from 4 different schools in Gaelong City, Korea where a large military base is located. A total of 43 responses were rejected because the replies were judged to be unreliable or inappropriate; subsequently, 387 questionnaires were used for the analysis. There were 195 adolescents from nonmilitary families and 192 adolescents from military families.

Table 1 shows the characteristics of the subjects. There were 102 male students (52.3\%) and 93 female students $(47.7 \%)$ in the non-military adolescent group and there were 96 male students $(50.0 \%)$ and 96 female students $(50.0 \%)$ in the adolescent of soldiers group. The history of school transfers since the start of elementary school showed that 91 
The Influence of Family Dynamic, Attachment to Fathers, Attachment to Friends, Self-esteem, and Stress on School Adaptation: A Comparative Study of Addolescents from Non-military Families and Military Families 5

Table 1. The General Characteristics of the Subjects

$(\mathrm{N}=387)$

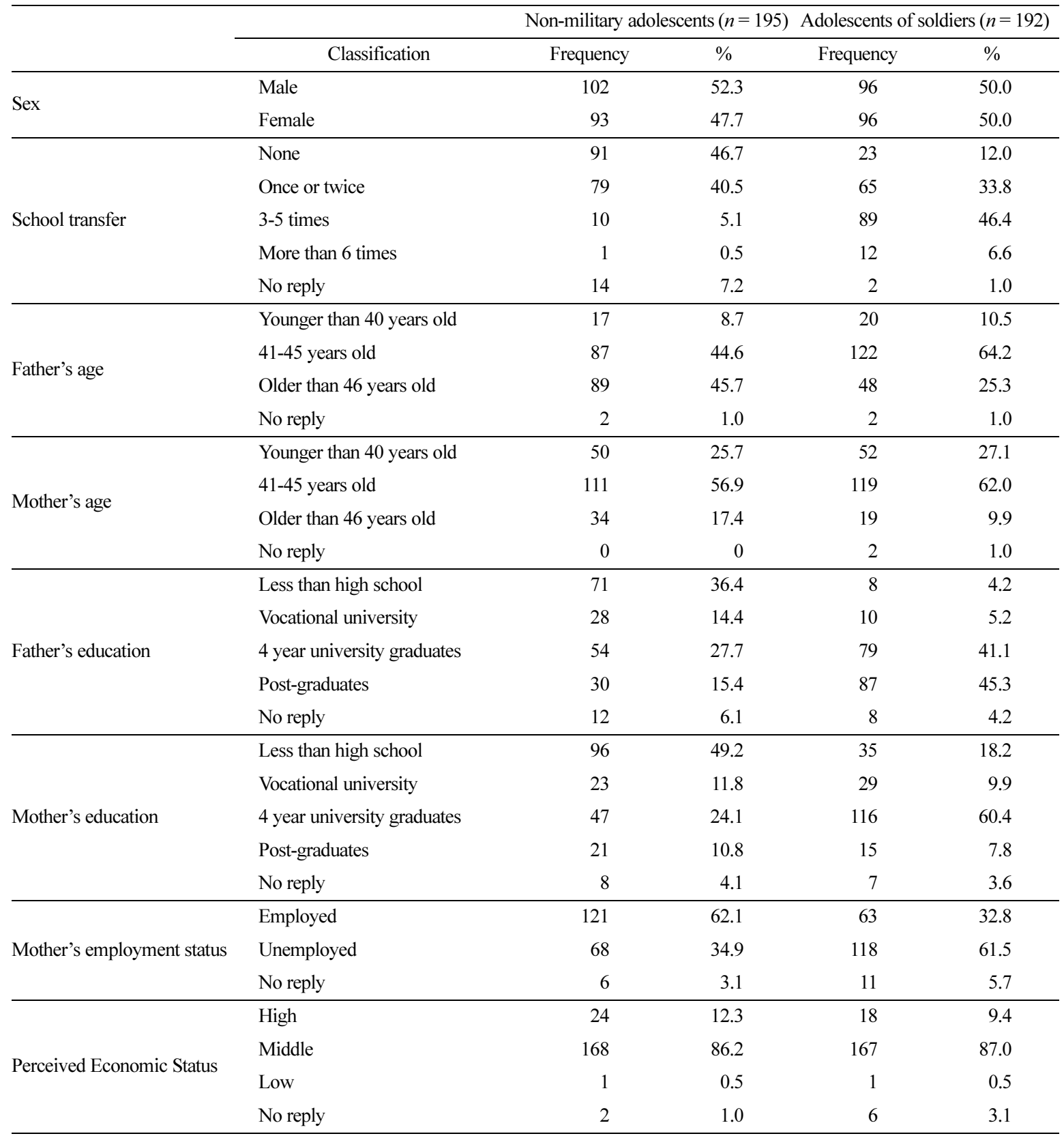

students (46.7\%) from the non-military adolescent group never transferred, 79 students $(40.5 \%)$ transferred once or twice, 10 students (5.1\%) transferred 3-5 times and 1 student transferred more than 6 times $(0.5 \%)$. In the adolescent of soldiers group, 89 students (46.4\%) transferred 3-5 times, 65 students $(33.8 \%)$ transferred once or twice, 23 students $(12.0 \%)$ never transferred and 12 students transferred more than 6 times. All of the adolescents were lived with their parents together currently.

\section{Measurement}

Family dynamic The 'Family Adaptability and Cohesion Evaluation Scale III: FACES III' 
questionnaire devised by Olson in 1985 was used to measure family dynamic as perceived by adolescents. FACES III was developed to evaluate the family system and is a self-reporting questionnaire that consists of 20 questions. Each item ranges from 'not at all' ( 1 point) to 'very much so' (5 point); consequently, a higher score indicates a smoother a family dynamic. For example, there is an item asking our family helps each other when we have difficulties. The Cronbach's $\alpha$ value in this study was .86 .

Attachment to fathers The Korean modified version of inventory of Peer Attachment (IPPA, devised by Armsden and Greenberg with 10-20 years old adolescents, 1987), IPPA-R (Ok, 1998) measured the attachment level of adolescents to fathers. There are 25 questions that can be answered between 'not at all' ( 1 point) and 'very much so' (4 point). A lower score indicates higher attachment levels. The value of Cronbach's $\alpha$ was .93.

Attachment to friends A Korean IPPA-R (Ok, 1998) modified version of the Inventory of Peer Attachment (IPPA, devised by Armsden and Greenberg with 1020 years old adolescents, 1987) measured the attachment level of adolescents to friends. There were 25 questions with a range of answers from 'not at all' (1 point) to 'very much so' (4 point). A higher score indicates higher attachment levels. For example, there is an item asking 'my friends notice when I feel low. The value of Cronbach's $\alpha$ was 90 .

Self-esteem The Self-esteem Scale devised by Rosenberg (1965) was used to measure the level of self-esteem. This scale consists of 10 items that can be answered from 'not at all' (1 point) to 'very much' (4 point). A higher score denotes a higher level of self-esteem. There is a question such as 'I think I am worth it' and the value of Cronbach's $\alpha$ was .82 .

Stress The Scale for Adolescent Stress devised by Kim and Lee (1996) consists of 17 items that measured stress level. Each item can be answered from 'not at all' ( 1 point) and 'very much' (5 point) and a higher score denotes a higher level of stress.
For example, there is a question asking 'I am stressed by my parents because of my examination score' and the value of Cronbach's $\alpha$ was .88.

School adaptation School Adaptation Scale (Kim, 2000) measured the level of school adaptation. It consists of 41 items with answers that ranged from 'not at all' ( 1 point) to 'very much' (5 point). A higher score denotes a superior ability of a student to adapt to school. For example, there is an item such as 'I do well as the school demands' and the value of Cronbach's $\alpha$ was .94.

\section{Procedure and Data Analysis}

A mock investigation was conducted with 12 firstgrade middle school students in Chungnam Korea in November 2010 with self-reporting questionnaires. Analysis was done by SPSSWIN 17.0 and Cronbach's $\alpha$ was used to examine the reliability of the investigations. The percentages, average scores and standard deviations were calculated; in addition, $\mathrm{t}$ test and multiple regression analysis were conducted.

\section{RESULTS}

We examined the study variables as well as calculated the average score and the standard deviation prior to analysis. <Table $2>$ shows the results.

The differences in family dynamic, attachment to fathers, attachment to friends, self-esteem, stress and school adaptation between the non-military adolescents group and adolescents of soldiers group

Table 3 shows the $t$-test results of the nonmilitary adolescents group and adolescents of soldiers group and examined the differences in family dynamic, attachment to fathers, attachment to friends, self-esteem, stress and school adaptation. There were significant difference in the attachment to fathers $(t=2.41, p<.05)$, self-esteem $(t=3.08, p<$ $.01)$, stress $t=-2.36, p<.05)$ and school adaptation $(t=2.37, p<.05)$. The non-military adolescents perceived a higher attachment to fathers $(M=3.07$, $S D=.45)$ than adolescents of soldiers $(M=2.95$, $S D=.49)$ and the self-esteem of non-military adoles- 
Table 2 The Mean Score and Standard Deviation of Family Dynamic, Attachment to Fathers, Attachment to Friends, Self-esteem, Stress and School Adaptation

\begin{tabular}{lccc}
\hline Variables & Statistical value & Score range & The minimum-maximum score \\
\hline Family dynamic & $1 \sim 5$ & $2.00 \sim 5.00$ & $3.52(.50)$ \\
Attachment to fathers & $1 \sim 4$ & $1.68 \sim 4.20$ & $3.01(.47)$ \\
Attachment to friends & $1 \sim 4$ & $1.48 \sim 4.00$ & $2.98(.39)$ \\
Self-esteem & $1 \sim 4$ & $1.60 \sim 4.00$ & $2.92(.45)$ \\
Stress & $1 \sim 5$ & $1.00 \sim 5.00$ & $2.64(.71)$ \\
School adaptation & $1 \sim 5$ & $1.88 \sim 5.00$ & $3.20(.52)$ \\
\hline
\end{tabular}

Table 3. Differences in Family Dynamic, Attachment to Fathers, Attachment to Friends, Self-esteem, Stress and School Adaptation between the Non-military Adolescents Group and the Adolescents of Soldiers Group

\begin{tabular}{lccc}
\hline & Non-military adolescents $(n=195)$ & Adolescents of soldiers $(n=192)$ & \multirow{2}{*}{$t$} \\
\cline { 2 - 3 } & $M(S D)$ & $M(S D)$ & 1.88 \\
\hline Family dynamic & $3.57(.48)$ & $3.47(.52)$ & 2.41 \\
Attachment to fathers & $3.07(.45)$ & $2.95(.49)$ & 1.07 \\
Attachment to friends & $3.00(.38)$ & $2.95(.41)$ & $3.08^{* *}$ \\
Self-esteem & $2.99(.44)$ & $2.85(.46)$ & $-2.36^{*}$ \\
Stress & $2.56(.73)$ & $2.73(.67)$ & $2.37^{*}$ \\
School adaptation & $3.26(.51)$ & $3.14(.53)$ & \\
\hline
\end{tabular}

$* p<.05 . * * p .01$

cents $(M=2.99, S D=.44)$ appeared to be higher than adolescents of soldiers $(M=2.85, S D=.46)$. The adolescents of soldiers $(M=2.73, S D=.67)$ had higher level of stress than non-military adolescents $(M=2.56, S D=.73)$ and the school adaptation level of non-military adolescents $(M=3.26, S D=.51)$ was higher than adolescents of soldiers $(M=3.14, S D=$ .53).

The impact of variables that affect school adaptation

$<$ Table $4>$ shows the results of multiple regression analysis to examine the impact of variables that affect school adaptation. Prior to multiple regression analysis, VIF index and Durbin-Watson statistics indicated the basic level of family satisfaction. The VIF index was between 1.23-1.84 and significantly lower than 10; therefore, there was no multicollinearity. Dubin-Watson statistics showed a VIF index of 1.76-1.98 with no correlations between the errors; consequently, the basic criteria for multiple regression analysis was met. Family dynamic, attachment to fathers, attachment to friends, and self-esteem were independent variables for the multiple regression analysis.

Family dynamic $(\beta=.28, p<.001)$, stress $(\beta=$ $-.26, p<.01)$, and attachment to fathers $(\beta=.20$, $p<.05)$ impacted the level of school adaptation by non-military adolescents in order and its explanatory adequacy was $18 \%$. Non-military adolescents adapted better to school when they had high family dynamic, low stress and a high attachment level to fathers.

Family function $(\beta=.39, p<.001)$ and attachment to friends $(\beta=-.26, p<.01)$ had the most significant impact on school adaptation by the adolescents of soldiers and its explanatory adequacy was $23 \%$. Adolescents of soldiers adapted better to school when they had a high family dynamic and a high attachment level to friends. 
Table 4. Variables that affect School Adaptation by Adolescents

$(\mathrm{N}=387)$

\begin{tabular}{|c|c|c|c|c|}
\hline & \multicolumn{4}{|c|}{ School adaptation } \\
\hline & \multicolumn{2}{|c|}{ Non-military adolescents $(n=195)$} & \multicolumn{2}{|c|}{ Adolescents of solders $(n=192)$} \\
\hline & B & $B$ & $\mathrm{~B}$ & $\beta$ \\
\hline Family dynamic & .30 & $.28 * * *$ & .40 & $.39 * * *$ \\
\hline Attachment to fathers & .22 & $.20^{*}$ & -.06 & -.06 \\
\hline Attachment to friends & .11 & .08 & .34 & $.26 * * *$ \\
\hline Self-esteem & .14 & .12 & .05 & .04 \\
\hline Stress & -.18 & $-.26^{* *}$ & .06 & .08 \\
\hline$R^{2}$ & \multicolumn{2}{|c|}{.18} & \multicolumn{2}{|c|}{23} \\
\hline$F$ & \multicolumn{2}{|c|}{$8.31 * * *$} & \multicolumn{2}{|c|}{$11.26^{* * *}$} \\
\hline$D W$ & \multicolumn{2}{|c|}{1.76} & \multicolumn{2}{|c|}{1.98} \\
\hline
\end{tabular}

${ }^{*} p<.05 .{ }^{* *} p<.01 .{ }^{* * *} p<.001$.

\section{DISCUSSION AND CONCLUSION}

This study examined the differences in school adaptation between non-military adolescents and the adolescents of soldiers. First, non-military adolescents perceived a higher level of attachment to fathers and self-esteem than the adolescents of soldiers; however, the stress level of adolescents of soldiers was higher than non-military adolescents and non-military adolescents adapted better to school than the adolescents of soldiers.

These results are due to frequent transfers of duty stations for fathers, deployments and shiftwork; consequently, the attachment to fathers was not well established for adolescents of soldiers. Therefore, communication and empathy are required to establish trust that facilitates an intimate and positive relationship between professional soldiers and their children. Additionally, the attachment theory of Bowlby argues that 'the establishment of attachment itself' is the salient point rather than 'reckless devotion'. The primary subject is the mother but can also be the father (or others) according to cultural characteristics (Bowlby, 1969). Therefore, an absence of the father can be supplemented by an extended relationship with the mother (or others) to help the adolescents of soldiers achieve positive development.

Non-military adolescents' self esteem was higher than the adolescents of soldiers and it is necessary to provide direction in order to obtain positive self- esteem and adapt to different environments or situations. Long-term programs will work better than short-term programs because established selfesteem cannot be rectified rapidly (Chung, 2006; Cole, Maxwell, Martin, Peeke, Seroczynski, Tram, Hoffman, Ruiz, Jacquez, \& Maschman, 2001).

The stress level of adolescents of soldiers was higher than non-military adolescents. The study of Kim (2001) showed that adolescents of soldier change schools more frequently; subsequently, the stress level in friendship is higher than those of nonmilitary adolescents. This stress caused by the instability of households is due to frequent movements, the paternal role performance influence by the occupational characteristics and studying and grade expected to be higher.

Non-military adolescents did better at school adaptation than the adolescents of soldiers. This result is different from the study result of Lee (2001) because the subjects of this study were adolescents who were more sensitive rather than young children in terms of interpersonal relationships with friends or teachers or the ability to study. Various scholastic aptitude enforcement programs (including art and physics) in the United States support 12-18 years old children of soldiers and provide a continuity of services through close collaborations between military bases, the family, the school and the community for education (Park, 2009). It is necessary to develop a program that helps the adolescents of soldiers, who 
frequently transfer schools and necessary to secure professionals who understand needs and requirements to initiate an effective program.

Secondly, the results of multiple regression analysis indicate that family dynamic, attachment to fathers, and stress influenced school adaptation by non-military adolescents; however, family dynamic and attachment to friends influenced school adaptation by adolescents of soldiers. Family dynamic is important and various education programs to improve family dynamic can be achieved through a social support system to aid school adaptation. The United States recognized the importance of family relationships since 1980 and made substantial invests into Soldier and Family Assistance Centers (SFACs) (Daley, 1999). It is more effective to base programs on the needs of each stage of a family when family supporting programs are run (Park, 2009).

Child bonding was traditionally considered the responsibility of the mother. However, one of variables to predict school adaptation is attachment to fathers. It is necessary to develop effective programs for fathers to understand adolescent children and establish emotionally intimate and positive attachments.

Kang (2000) argued that maternal roles influence paternal role performance and that it is necessary to include mothers in parent role programs.

Stress is also a variable related to school adaptation. Kim (2008) argued that the stress related to studying is the highest for the daily life stresses of adolescents (followed by parental, materials, appearance and peer stress). There is an absence of healthy methods and conditions to remove stress even though the educational environment of Korea is a major factor for adolescent stress due to the pressure to succeed on the Korean Scholastic Aptitude Test (KSAT) for university entrance. Therefore, it is necessary to promote educational environments that focus on subjective values for each student rather than focus on standardized achievements. Oh (2010) claimed that students adapted to schools better when they use active methods to cope with stress and suggests that adolescents should be directed to use available resources to cope with diverse situations.

Attachment to friends was an important variable for the adolescents of soldiers and is related to the research results of Picou and Carter (1976) that indicated that friendships among peers is more than simple encouragement and support. Attachment to friends helps children through the interpersonal modeling of each other. Programs are required that assist smooth interpersonal relationships, facilitate desirable friendships, recognize the importance of friendships, promote mutual respect and facilitate teamwork. Various after school activities to obtain desirable friendships and social skill should be organized because the relationship with friends is an important factor for school adaptation during adolescence (Kingery \& Erdley, 2007). Friendship and social skill promotion programs are essential for the adolescents of soldiers who frequently transfer duty stations.

Several limitations to this are noted. First, there is a significant difference in the education level of fathers and employment status of mothers between adolescents from non-military families and adolescents from military families in this study; consequently, family background may influence the results of the study. Second, the characteristics of military families depend upon the rank of the father; however, this study was not able to include the rank of fathers due to school policies that forbid the identification of rank. Third, our questionnaire did not include family income since adolescents did not have precise information about family income. Fourth, school education focused on grades and entrance examinations under a competitive atmosphere; however, school adaptation will be researched in more detail if the relation between study performance factors (such as grades and school adaptation as well as the variables that affect school adaptation) can be researched. Fifth, research is required that deals with the combined perceptions of parents, teachers and students instead of just parents, teachers or friends. Lastly, it is possible to obtain more effective results if prevention and intervention programs related to the adaptation of adolescents are developed through research that investigates variables that buffer the effects of school adaptation.

Despite of the limitations, this study investigated the differences in family dynamic, attachment to 
fathers, attachment to friends, self-esteem, stress and school adaption between non-military adolescents and adolescents of soldiers. This study showed that the variables that affect school adaption were family function, attachment to friends, self-esteem and stress for non-military adolescents versus the variables of family dynamic, attachment to fathers, attachment to friends and self-esteem for adolescents of soldiers. Especially, the significance of this study was to examine the variables that affect school adaption through a comparison of non-military adolescents and adolescents of soldiers to suggest the distinctive and multi-dimensional education based on the various circumstances of adolescents.

\section{REFERENCES}

Ahn, M. K. (1983). An analytical research on the education of military families' children. Master's Thesis, Yonsei University, Seoul: Korea.

Agnew, R., Brezina, T., Wright, J., \& Cullen, F. (2002). Strain, personality traits and delinquency: Extending general strain theory, Criminology, 40(1), 43-72.

Ainsworth, M., \& Bell, S. M. (1970). Attachment, exploration, and separation: Illustrated by the behavior of one-year-olds in a strange situation. Child Development, 41, 49-67.

Barnow, S., Lucht, M., \& Freyberger, H. J. (2005). Correlates of aggressive and delinquent conduct problems in adolescence. Aggressive Behavior, 31(1), 24-39.

Bascoe, S. M., Davies, P. T., Sturge-Apple, M. L., \& Cummins, E. M. (2009). Children's representation of family relationships, peer information processing, and school adjustment. Developmental Psychology, 45(6), 1740-1751.

Baumeister, R. F., Dori, G. A., \& Hastings, S. (1998). Belongingness and temporal bracketing in personal accounts of changes in self-esteem. Journal of Research in Personality, 32, 222-235.

Bowlby. J. (1969). Attachment and loss Vol. 1. Attachment. NY: Basic Books.

Bronfenbrenner, U. (1976). Research on fathering: Social policy and emergent perspective. In
Skolnick, A. \& Skolnick, J. (Eds.), Family in transition. Boston: Little, Brown and Company.

Brown, J. D., \& Mankowski, T. A. (1993). Self-esteem, mood, and self-evaluation: Changes in mood and the way you see you. Journal of Personality and Social Psychology, 64(3), 421-430.

Burchinal, M. R., Roberts, J. E., Zeisel, S. A., \& Rowley, S. J. (2009). Social risk and protective factors for African American children's academic achievement and adjustment during the transition to middle school. Developmental Psychology, 44(1), 286-292.

Caldwell, R. M., Wiebe, R. P., \& Cleveland, H. H. (2006). The influence of future certainty and contextual factors on delinquent behavior and school adjustment among African American adolescents. Journal of Youth and Adolescence, 35(4), 587-598.

Chapple, C. L. (2005). Self-control, peer relations, and delinquency. Justice Quarterly, 22(1), 89-106.

Choi, E. S. (2009). The social economic analysis followed by transfer of sufficiency model of human resources for national defense: Comparative study on the conscription and recruiting system. Master's Thesis, Korea University, Seoul: Korea.

Choi, M. H. (2010). The effects of perceived emotional intelligence and family functioning on the school related adjustment of middle school students. Master's Thesis, Cheongju University, Cheongju: Korea.

Choi, Y. J. (2005). A study on military personnel's school-aged children's quality of life and behavioral profiles. Master's Thesis, Seoul National University, Seoul: Korea.

Chung, I. C. (2006). Reciprocal relationship between self-esteem and juvenile delinquency. Korean Journal of Social Welfare Studies, 31, 133-159.

Cole, D. A., Maxwell, S. E., Martin, J. M., Peeke, L. G., Seroczynski, A. D., Tram, J. M., Hoffman, K. B., Ruiz, M. D., Jacquez, F., \& Maschman, T. (2001). The development of multiple domains of child and adolescent self concept: A cohort sequential longitudinal design. Child Development, 72(6), 1723-1746.

Daane, D. M. (2003). Child and adolescent violence. Orthopedic Nursing, 22(1), 23-31. 
Daley, J. G. (1999). Social work practice in the military. New York: The Haworth Press.

Danielsen, A. G. (2009). School-related social support and students' perceived life satisfaction. Journal of Education Research, 102(4), 303-318.

D'Zurilla, T. J., \& Nezu. M., (2007). Problem solving therapy: A positive approach to clinical intervention (3rd ed.). New York: Springer Publication.

Flouri, E., \& Buchanan, A. (2004). Early father's and mother's involvement and child's later educational outcomes. British of Educational Psychology, 74, 141153.

Freeman, H., \& Brown, B. B. (2001). Primary attachment to parents and peers during adolescence: Differences by attachment style. Journal of Youth and Adolescence, 30(6), 653-674.

Han, S. B. (1992). The relationship between children's self-concepts and family systems as analyzed by the circumplex model. Master's Thesis, Yonsei University, Seoul: Korea.

Han, T. Y. (2005). Adolescents' stress at school: Moderation effects of personality and emotional intelligence. Korean Journal of Psychology: General, 2(2), 177-197.

Jee, S. K. (2001). A study of relationship between adolescents' attachment, self-efficacy and adaptation to school life. Master's Thesis, Sogang University, Seoul: Korea.

Jon, B. J. (1974). Self-esteem: A test of its measurability. Journal of Yonsei, 11(1), 107-130.

Jung, M. J. (2005). Marital conflicts between parents, adolescent's self-esteem and school maladjustment. Master's Thesis, The Catholic University of Korea, Seoul: Korea.

Jung, Y. O. (2002). A study of relationship between adolescents' attachment, self-efficacy and adaptation to school life. Master's Thesis, Kyungsung University, Pusan: Korea.

Kalish, R. A., \& Knudston, F. W. (1976). Attachment versus disengagement: A life-span conceptualization. Human Development, 19, 171-181.

Kang, H. S. (2000). The relationship between school transfers, adjustment, and academic achievement of military family's children. Master's Thesis, Korea University, Seoul: Korea.

Kang, J. H. (2000). Perception on father's role of adolescents having military father. Master's thesis, Yonsei University, Seoul: Korea.

Kim, E. J. (2009). Teachers' perception on the adjustment to elementary school of students by learning styles and gender differences. Journal of Gongju National University of Education, 46(1), 37-52.

Kim, J. H. (2008). The effects of stress on adaptation to school of adolescents: The moderating effects of family support. Korean Journal of Family Welfare, 13(4), 161-183.

Kim, J. H., \& Lee. D, W. (1996). A study on strain and juvenile delinquency, Journal of Korean Criminological Review, 1, 13-165.

Kim, K. S. (2003). The effects of self-esteem program on middle school students' adaptation to school life. Master's Thesis, Cheju National University, Cheju: Korea.

Kim, M. R. (2002). Friendships and self-esteem in adolescence. Doctoral Dissertation, Chonnam National University, Chonnam: Korea.

Kim, S. J. (2001). Studies on the relationship between stress level of children of servicemen-civilians who work in the military and social support source, social support type. Master's Thesis, Hannam University, Daejeon: Korea.

Kim, S. K. (2008). The effects of daily stress on psychosocial adjustment of Korean high school students. Korean Journal of Youth Studies, 15(1), 381-406.

Kim, Y. R. (2000). An analysis on the validation of school learning motivation scale (A) \& schoolrelated coping scale (B) and relations between (A) \& (B). Journal of Hongik, 17, 3-37.

Kim, Y. R., \& Kim, T. E. (2004). Learner's stress, school-related coping and academic achievement. Journal of Hongik, 21, 5-31.

Kingery, J. N., \& Erdley, C. A. (2007). Peer experience as predictors of adjustment across the middle school transition. Education and Treatment of Children, 30(2), 73-88.

Kweon, S. Y., \& Yang, Y. S. (2007). Influences of psy- 
chological emotional state, learning motive and family function on adolescents' school adjustment. Korean Journal of Family Welfare, 12(3), 115-239.

Laird, R. D., Petti, G. S., Dodge, K. A., \& Bates, J. E. (1999). Best friendships, group relationships, and antisocial behavior in early adolescence. Journal of Early Adolescence, 19(4), 413-437.

Lee, E. H. (2001). A comparative study of the relationship of home environment and school adjustments of children from average and soldier families. Master's Thesis, Deajeon University, Deajeon: Korea

Lee, H. S. (1983). A study of high school students' home environments and values from military families. Master's Thesis, Yonsei University, Seoul: Korea.

Lee, J. Y. (2004). The effects of stress and parent-adolescent communication on suicide ideation. Master's Thesis, Chungang University, Seoul: Korea.

Lee, M. H. (2005). The effect of parent-adolescent communication and family functioning on school adjustment. Master's Thesis, Hongik University, Seoul: Korea.

Lee, M. J. (2001). The relation between mother's attitude of bringing up, school condition and adolescents depression: Medium change factor: "Selfesteem". Master's Thesis, Chungang University, Seoul: Korea.

Lee, S. H. (2005). The relations between parent attachment, peer attachment and school life adjustment in adolescents. Master's Thesis, Ewha Womans University, Seoul: Korea.

Lee, T. H. (2009). The influence by social capital, selfesteem, peer relationship on adolescents' school adjustment. Master's Thesis, Hanyang University, Seoul: Korea.

Lim, J. A., \& Lee, I. S. (2006). A study on the adolescents' family strengths and school adjustment. The Journal of Child Education, 15(2), 37-62.

Lim, S. K., \& Lee, H. S. (2007). The effects of selfesteem, relationships with parents and peer relationships on adolescents' school adjustment. Journal of Korean Home Economics Education Association,
19(3), 169-183.

Lim, S. Y. (2006). The impact of perceived family environments on school adjustment among middle school students. Journal of Social Welfare Development, 12(4), 339-379.

Lim, Y. J., \& Rah, Y. M. (2003). The links between parent-child relationship and self-esteem and loneliness in adolescents. Journal of Adolescent Welfare, 5(2), 61-69.

Long, B. H., Henderson, E. H., \& Ziller, R. C. (1968). Development changes in the self-concept during middle school. Merrill-Palmer Quarterly, 13(2), 201215.

Marchant, K. H., \& Medway, F. J. (1987). Adjustment and achievement associated with mobility in military families. Psychology in the School, 24, 289-294.

McGee, R., \& Williams, S. (2000). Does low self-esteem predict health compromising behaviors among adolescence? Journal of Adolescence, 23(6), 569-582.

Min, H. Y., \& Kawn, K. N. (2004). The school adjustment of children of low-income families. Korean Journal of Child Studies, 25(2), 81-92.

Moon, K. S. (2008). Academic stress and mental health of adolescents: The role of self-control and emotion regulation. Korean Journal of Child Studies, 29(5), 285-299.

Moon, S. Y. (2009). A study on the relationship between school transfer experience and school life adaptation: Focus for military children. Master's Thesis, Gongju National University of Education, Gongju: Korea.

Morman, M. T., \& Floyd, K. (2002). A "hanging of fatherhood" effects on affectionate communication, closeness, and satisfaction in men's relationships with their fathers and their sons. Western Journal of Communication, 66(4), 395-411.

Nam, Y. J., \& Park, T. Y. (2009). The mediating effect of self-esteem in the relation between adolescent's family strengths and school adaptation. Korean Journal of Youth Studies, 16(4), 47-71.

Oh, J. S. (2010). The relation of affection of middle school students to parents and strategies to manage stress, and adaptation to school. Master's The- 
sis, Kangwon National University, Kangwon: Korea.

Olson. D. H., Portner. J., \& Lavee, Y. (1985). FACES III. Family social science. University of Minnesota. St. Paul, Minnesota.

Ok, J. (1998). The relationship between attachment security and depression in adolescence: Focusing on the mediating effect of perceived competence. Master's Thesis, Ewha Womans University, Seoul: Korea.

Park, M. E. (2009). A study on the utilization of social welfare system for military family support policy. Korean Academy of Military Social Welfare, 2(2), 1-24.

Park, Y. S. (2003). A study on the factors influencing school adjustment of adolescents from divorced families. Master's Thesis, Ewha Womans University, Seoul: Korea.

Picou, J. S., \& Carter, T. M. (1976). Significant other influence and aspiration. Sociology of Education, 49(1), 12-22.

Rosenberg, M. (1965). Society and the adolescence selfimage. NJ: Princeton University Press.

Shek, D. T. L. (2002). Family functioning and psychological well-being, school adjustment, and problem behavior in Chinese with and without economic disadvantage. Journal of Genetic Psychology, 163(4), 497-502.

Shim, S. J. (2003). The effects of degree of attachment to peers and degree of self-esteem on middle school students' school life. Master's Thesis, Ewha Womans University, Seoul: Korea.

Suh, J. H., \& Yoo, A. J. (2001). Adolescent friendships: Differences in function, structure, and satisfaction by internet and real life variables. Korean Journal of Child Studies, 22(4), 149-166.

Yang, J. H. (2002). The effect of attachment to parents on children's self-esteem and learning motivation. Master's Thesis, konkuk University, Seoul: Korea.

Yang, S. M., \& Yoo, Y. J. (2003). Effects of self-esteem, healthiness of family, and social demographic variables on the school life adjustment in rural adolescents. Journal of the Korean Home Economics Association, 41(9), 121-134.

Yoon, S. K. (2004). Relationships between self-esteem and the experience and adaptation of stress in elementary and middle school student. The Journal of Child Education, 13(2), 239-251.

Yoon, S. Y. (1999). Relationship between fathering practices and children's social adjustment. Master's Thesis, Korea University, Seoul: Korea

Youniss, J., \& Smollar, J. (1985). Adolescence' relationship with mothers, fathers and friends. University of Chicago Press, Chicago.

Received October 9, 2013

Revised December 1, 2013

Accepted December 16, 2013 